\title{
Welfare Tradeoffs in U.S. RAIL Mergers
}

\author{
MARC IVALDI \\ University of Toulouse (IDEI), EHESS and CEPR, France
}

GERARD MCCULLOUGH

University of Minnesota, USA

March 2005

\begin{abstract}
Since the publication by Williamson (1968) of his seminal paper on antitrust there has been a growing recognition by regulators of the need to assess tradeoffs between merger-related efficiency gains and merger-induced increases in market power. This paper addresses that need by presenting a structural econometric model of recent mergers in the U.S. rail industry. The paper extends the structural methodology by evaluating actual (as opposed to simulated) merger effects and by incorporating parametric estimates of merger efficiencies. The paper's empirical finding is that consumer surplus in U.S. rail freight markets increased by about 30 per cent between 1986 and 2001 despite dramatic industry consolidation.
\end{abstract}

Keywords: merger analysis, differentiated product markets, logit models, railroads

JEL Classification: L11, L13, L41, L92 


\section{Introduction}

Since the publication by Williamson (1968) of his seminal paper on antitrust there has been a growing recognition by merger authorities of the need to assess tradeoffs between merger-related efficiency gains and merger-induced increases in market power. The U.S. Justice Department and the Federal Trade Commission describe these tradeoffs in some detail in the Horizontal Merger Guidelines jointly issued in 1992 (and revised in 1997). The Guidelines state:

Competition usually spurs firms to achieve efficiencies internally. Nevertheless, mergers have the potential to generate significant efficiencies by permitting a better utilization of existing assets, enabling the combined firm to achieve lower costs in producing a given quantity and quality than either firm could have achieved without the proposed transaction. Indeed, the primary benefit of mergers to the economy is their potential to generate such efficiencies.

[These]...can enhance the merged firm's ability and incentive to compete, which may result in lower prices, improved quality, enhanced service, or new products.

The European Economic Commission makes a similar acknowledgement in its new 2004 Merger Guidelines.

The Commission considers any substantial efficiency claim in the overall assessment of the merger. It may decide that, as a consequence of the efficiencies that the merger brings about, there is no ground for declaring the merger incompatible with the common market [...]. This will be the case when the Commission is in a position to conclude on the basis of sufficient evidence that the efficiencies generated by the merger are likely to enhance the ability and incentive of the merged entity to act pro-competitively for the benefit of consumers, thereby counteracting the adverse effects on competition which the merger might otherwise have.

Concern with the assessment of merger effects extends also to more specialized agencies such as the Federal Communications Commission (FCC) and the Surface Transportation Board (STB) whose responsibility for economic regulation of particular industries includes merger oversight. In its recently published Rules Governing Major Railroad Mergers and Consolidations, for example, the STB states that 'mergers serve the public interest only when substantial and demonstrable gains in public benefits-improved service and safety, enhanced competition, and greater economic efficiency outweigh any anticompetitive 


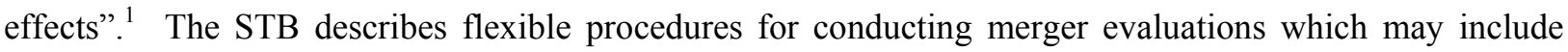
"econometric and other statistical analyses".

This paper responds to the need for empirical tools for merger assessment by presenting the results of a structural econometric analysis of the welfare effects of U.S. rail mergers for the period 1986-2001. A structural analysis in this context is a system of equations which expresses 1) the demand conditions prevailing in a market (or set of interrelated markets), 2) cost (or supply) conditions in the market (or markets) under study, and 3) hypotheses regarding the strategic behavior of market participants usually in the form of pricing equations. Werden, Froeb and Scheffman (2004) stress the potential usefulness of such models for merger assessment, especially when these models are combined with standard evidentiary analyses of consumers, competitors and institutions. The model presented here builds on the work of Anderson, de Palma and Thisse (1992), Berry (1994), Shapiro (1996), Hausman and Leonard (1997), Nevo (2000), Ivaldi and Verboven (2000), and others who have developed the theory of differentiated product markets into a tool for merger analysis.

The basic assumptions in the paper are that railroads are multiproduct firms and that they compete as oligopolists with each other and with other modes in national freight markets. Freight services are differentiated by shipment types (bulk versus general freight) and by firm characteristics (especially network characteristics). The methodological innovation in the paper is to use a flexible cost function to incorporate parametric estimates of merger efficiencies into the structural model. Because there is good public data on U.S. freight railroads available the paper also evaluates actual (as opposed to simulated) merger effects. Werden, Froeb and Sheffman note that there are "surprisingly few" such studies and that these can help us to refine the tools for merger analysis.

The empirical finding of the paper is that between 1986 and 2001 consumer surplus in rail freight markets has increased by about 25 per cent despite the consolidation of 36 Class I railroad firms into nine. This finding is not inconsistent with results from other researchers who have studied the transformation of the U.S. railroad industry in the last quarter of the $20^{\text {th }}$ Century. An earlier study by Berndt, Friedlaender, Wang Chiang and Vellturo (1993), based on data from 1974-1986, found that mergers contributed significantly to railroad cost savings. More recent studies by Breen (2004) and Wilson and Bitzan (2004) reach the same conclusion. What the current paper adds are the critical demand-related aspects of rail freight markets.

The remainder of this paper is organized as follows. Section II provides contextual background on the railroad merger phenomenon. Section III proposes the theoretical model of the U.S. freight market.

\footnotetext{
${ }^{1}$ STB Guidelines, p. 71.

${ }^{2}$ Ibid., p. 85.
} 


\section{Welfare TRADEOFFs IN U.S. RaIL MERGERS}

Section IV describes the available data. Section V presents the regression results. Section VI states the paper's conclusions.

\section{Overview of U.S. Railroads and Railroad Mergers}

Mergers have been a dominant aspect of U.S. railroading for almost the entire 175-year history of the industry. The first railroads, built in the 1830s and 1840s, were small, privately-owned enterprises, designed to provide short-haul passenger and freight services especially to agricultural producers. ${ }^{3}$ During the second half of the 19th century and the early part of the 20th century these smaller railroads were cobbled together into much larger systems by a first wave of mergers and consolidations. ${ }^{4}$ This expansionary first wave continued until the 1920s when it was inadvertently halted by government intervention. The Interstate Commerce Commission, formed in 1887 to regulate the industry, was originally tolerant of mergers but at Congress's direction in 1929 issued a Complete Plan of Consolidation which required that any proposed consolidation adhere to a national plan drafted by Harvard professor William Z. Ripley. This effectively halted the merger process until the Ripley Plan was repealed by the Transportation Act of 1940.

Mergers and consolidations resumed again after World War II as the railroads lost their intercity passenger markets to automobiles and planes, and faced increasing competition from trucks and barges in their freight markets. ${ }^{5}$ The second wave of mergers, nearly all of these were defensive mergers proposed to cut costs and/or avert financial crises, continued until 1970. Between 1940 and 1970 railroad share of the intercity freight market (ton-miles) dropped from 61.3 percent to 39.8 percent, and the number of larger Class I railroads dropped from 131 to 71 . The biggest merger of the period - the Penn Central merger failed spectacularly in 1970 and this led, first, to a government-financed reorganization of Northeastern railroads (Conrail), and then to a softening and revision of the rail regulatory framework (the Staggers Act of 1980).

The Staggers Act gave railroads the commercial freedom to enter into contracts with major customers and to exit from markets where they could not compete with trucks. It also streamlined the merger process. The result was a dramatic degree of rationalization and a third wave of mergers and

\footnotetext{
${ }^{3}$ The first U.S. railroad, The Baltimore and Ohio, operated on 13 miles of track in 1830.

${ }^{4}$ Wilner (1996) reports that there were over 900 consolidations during the period between 1870 and 1920 as the U.S. system grew from about 20,000 route miles to over 300,000 route miles. Some 425 of these took place between 1880 and 1888 .

${ }^{5}$ Railroads also suffered from changes in land use policies and in the composition of output in the U.S. This is a more complex story that goes well beyond the aims of this paper.
} 
consolidations of increased size and scope. Between 1970 and 2001, a period in which rail share of the freight market stabilized, Class I railroads reduced their locomotive stocks by 30 percent, their network size by 40 percent, and their workforces by 60 percent. Mergers and consolidations reduced the number of Class I railroads from 71 to eight. ${ }^{6}$ The major mergers that took place during this consolidation phase are summarized in Table 1.

\section{[INSERT TABLE 1. RAILROAD MERGERS 1985-2000]}

Customer response to the third wave of mergers and consolidations has been ambivalent. On the one hand, the rationalization of workforce and physical plant has led to a significant decrease in unit operating expenditures, and these appear, to some extent, to have been passed on to shippers in the form of lower rates. On the other hand, railroad customers, especially smaller customers, have felt increasingly threatened by a perceived lack of rail alternatives. ${ }^{7}$ The increase in the Herfindahl index during the period is shown in Table 2. ${ }^{8}$ In addition, the recent mergers of Burlington Northern/Santa Fe and Union Pacific/Southern Pacific brought with them significant merger-related service disruptions. These developments led to a decision by the STB in March, 2000 to impose a 15-month moratorium on rail mergers and to reevaluate the agency's merger policy. The moratorium ended in June, 2001 with issuance of the Railroad Consolidation Procedures cited above, but the policy discussion of railroad mergers - the debate over increased efficiency versus increased market power - continues.

[INSERT TABLE 2. HERFINDAHL INDICES 1985-2000 ]

\section{Theoretical Model}

The methodological aim of this paper is to develop a structural econometric model for evaluating mergers in oligopoly markets where - as in the railroad case - there are significant cost complementarities

\footnotetext{
${ }^{6}$ The Railroad Passenger Act of 1970, which formed Amtrak, had relieved private railroads of the responsibility to provide passenger service.

The mergers are not the full story. As Class I railroads have exited markets, smaller, short-line railroads have entered. However, these firms still account for only about seven percent of rail movements, according to AAR estimates.

${ }^{8}$ The Herfindahl index which we have calculated here is based on a railroads share of Class I industry-wide carloads for a given year. This measure probably understates the degree of concentration since it does not take into account the fact that rail traffic tends to be geographically concentrated on eastern versus western railroads. We have used a nationwide measure because many of the firms who use railroads operate in national markets which span the two regions.
} 


\section{Welfare TRADEOFFs IN U.S. RaIL MERGERS}

across products. We model these markets as oligopolistic because we recognize that there are various factors besides freight rates which influence a shipper's decision to use a particular railroad or an alternative freight provider such as a barge or truck company. This means that each freight firm produces services which are differentiated from those of other firms.

The most obvious characteristic which differentiates a railroad's services is the placement of its track system relative to other transportation infrastructure and to the production and distribution activities of potential freight customers. The degree of market power that a particular railroad enjoys in a given market is largely a function of the relative advantage or disadvantage that its track system provides. These advantages vary considerably across firms and across markets, but our assumption is that on a dense network like the U.S. freight system with the possibility of truck or barge alternatives or alternative rail routings the degree of market power will never be absolute. ${ }^{9}$

\section{A. Demand}

We assume that there are three separate and independent freight transportation markets in which railroads compete among themselves and with other modes. The markets are bulk, intermodal and general freight. In each of these markets the shipper decides first the mode of transport - rail or other - and, if it has chosen rail, which particular railroad. We assume that there are $\mathrm{h}+1$ service providers with $h=0$ corresponding to the product "other transport modes." So there are $H$ railroads and $G$ markets corresponding to the $G$ types of commodities that can be shipped.

On the demand side, the customers of the railroad firms are freight shippers or receivers - whichever firm makes the shipment decision. Following the earlier work of McFadden (1981) and extensions by Anderson, de Palma and Thisse (1992), Berry (1994) and others, we assume that each shipper/receiver has a deterministic "utility function" consistent with its profit maximizing objectives. However, neither we nor the profit maximizing railroads can perfectly observe all of the characteristics influencing shipper/receiver decisions. Therefore, we decompose shipper/receiver utility into two components, one a function of known characteristics common to all shippers in a market, the other a random variable representing unobservable characteristics which influence the individual shipper/receiver decision.

\footnotetext{
${ }^{9}$ Grimm and Winston (2000) estimate in a recent Brookings study that about 15 percent of railroad freight movements are "captive" movements where origin and destination points are controlled by a single railroad. We have no reason to doubt this assessment which is based on a comprehensive survey of rail users. Our assumption though is that on the U.S. network there will always be routing or modal alternatives (however circuitous and expensive) even for shippers whose origin and/or destination points may be captive.
} 
Formally, let $U_{g h}^{n}$ be the utility (profit) that shipper $n$ receives when selecting railroad $h$ (or another transport mode) in market $g(g=1,2, \ldots, G), V_{g h}$ the systematic component common to shippers in $g$, and $v_{h}^{n, g}$ the unobserved characteristics of $n$. We then have

$$
U_{g h}^{n}=V_{g h}+v_{g h}^{n}
$$

The systematic utility that a shipper in market $g$ receives from using railroad $h$ can be further decomposed into a mean utility component $\left(\bar{V}_{g h}\right)$ common to all shippers who use $h$, a price effect, and a random component ()$\left(\xi_{\mathrm{gh}}\right)$ representing the unobserved components in $V_{g h}$. The expression for $V_{g h}$ then is

$$
V_{g h}=\bar{V}_{g h}-\alpha_{g} p_{g h}+\xi_{g h},
$$

or, letting $X_{g}$ represent a matrix of demand-related variables in market $g$ and $\beta_{g}$ a vector of parameters,

$$
V_{g h}=X_{g} \beta_{g}-\alpha_{g} p_{g h}+\xi_{g h}
$$

Of course we do not observe shipper utility. The unobserved component of the utility, $v_{g h}^{n}$, is itself decomposed as

$$
v_{g h}^{n}=\zeta_{h}^{n}+\left(1-\sigma_{g}\right) \varepsilon_{g h}^{n}
$$

The second and the third term, $\zeta_{h}^{n}$ and $\varepsilon_{g h}^{n}$, are random variables reflecting shipper $n^{\prime}$ s deviation from the mean valuation. The term $\zeta_{h}^{n}$ is the unobserved part of shipper $n$ 's utility that affects the choice of mode, whereas the term $\varepsilon_{g h}^{n}$ is the unobserved part of shipper $n$ 's utility that affects the choice of railroad firm $h$. The parameter $\sigma_{g}$ lies between 0 and 1 and measures the correlation of the shippers' utility across firms. If $\sigma_{g}=1$, there is a perfect correlation of preferences for firms within the choice of mode; so the railroads are perceived as perfect substitutes. As $\sigma_{g}$ decreases, the correlation of preferences across railroads decreases. 


\section{Welfare TRADEOFFs IN U.S. RaIL MERGERS}

If $\sigma_{g}=0$, there is no correlation of preferences: shippers are as likely to switch to other transport modes as to other railroads in response to a price increase. In this case, we have the standard logit model in which all railroads and all other transport modes compete symmetrically.

Each shipper $n$ chooses the carrier $h$ (a railroad or the other transport modes) that maximizes utility. To compute the probability that a shipper chooses product $h$, the nested logit model assumes that the random variables $\zeta_{h}^{n}$ and $\varepsilon_{g h}^{n}$ have distributions such that $\zeta_{h}^{n}$ and $\zeta_{h}^{n}+\left(1-\sigma_{g}\right) \varepsilon_{g h}^{n}$ have the extreme value distribution. Normalizing the mean utility level for the other transport modes to 0 , i.e., $V_{g 0}$, the probability $s_{g h}$ that a shipper chooses product $g$ is given by the following formula:

$$
s_{g h}=\frac{\exp \left(V_{g h} /\left(1-\sigma_{g}\right)\right)}{D_{g}} \frac{D_{g}^{1-\sigma_{g}}}{1+D_{g}^{1-\sigma_{g}}},
$$

where $D_{g}$ is defined by:

$$
D_{g}=\sum_{h=1}^{H} \exp \left(V_{g h} /\left(1-\sigma_{g}\right)\right)
$$

For the model to be consistent with (random) utility maximization, $\alpha$ has to be positive and $\sigma_{g}$ has to lie between 0 and 1 . At the aggregate level, the choice probability $s_{g h}$ coincides with the market share of product $j$. The total quantity shipped by railroad $h, y_{g h}$, is simply given by the probability that a shipper chooses product $h$ times the market size $Y_{g}$ :

$$
y_{g h}=s_{g h} Y_{g} .
$$

Equation (5) can be restated as

$$
\ln s_{g h}-\ln s_{g 0}=X_{g} \beta_{g}-\alpha_{g} p_{g h}+\sigma_{g} \ln s_{g h \mid H}+\xi_{g h}^{n} .
$$

where $s_{g h \mid H}$ is the market share of railroad $h$ on the rail market $g$ (i.e., without taking into account the other transport modes). It constitutes the first element of our structural model - a set of three separate demand equations for the markets in which railroads compete with each other and with other modes for market share. 


\section{B. Cost}

As multiproduct network firms, railroads engage in a vertical production process in which, at one stage, quasi-fixed land and other inputs (labor, energy, materials, equipment) are converted into maintained infrastructure (infrastructure outputs), and, at another stage, infrastructure outputs and the other inputs are converted into multiple commercial freight services. The production process itself is represented in our theoretical model by a flexible cost function which allows for the possibility of complementarities (or anticomplementarities) across outputs.

Let $C(y, w, t)$ be a variable cost of doing business in a year, where $w$ be an $I$-dimensional vector of input prices, $t$ a $J$-dimensional vector of quasi-fixed technological factors, $y$ an $G$ '-dimensional vector of outputs. The functional form we adopt is the multiproduct Generalized McFadden cost function applied to railroads by Ivaldi and McCullough (2003). This function is an extension of the single product functional form derived from McFadden (1978) and introduced by Diewert and Wales (1987). ${ }^{11}$ The main feature of this function is to provide an approximation of the true cost function on a set which can arbitrarily defined by the analyst. It is a desirable property when the objective is to perform a historical study.

Formally, the cost function is

$$
C=C(w, y, t)=a^{\prime} w+0.5 \frac{w^{\prime} \Delta w}{\theta^{\prime} w}\left(b^{\prime} y\right)^{2}+w^{\prime} \Lambda z+0.5\left(\theta^{\prime} w\right) z^{\prime} \Gamma z
$$

where $z$ is an $K$-dimensional vector $\left(K=G^{\prime}+J\right)$ that includes $y$ and $t, a$ is an unconstrained $I$-dimensional parameter vector, $\Delta$ is an $I$ by $I$ symmetric parameter matrix, $\Lambda$ is an $I$ by $K$ parameter matrix of nonnegative elements, $\Gamma$ is a $K$ by $K$ symmetric parameter matrix, and $b$ and $\theta$ are column vector of fixed parameters of dimension $G^{\prime}$ and $I$.

To estimate this function we use a set of factor demand equations which contain all of the parameters of the cost function. In accordance with Shephard's lemma, these are derived by differentiating (10) with respect to each of the elements in the input price vector $w$. The result is

$$
x=x(w, y, t)=\alpha+\left[\frac{\Delta w}{\theta^{\prime} w}-0.5 \frac{w^{\prime} \Delta w}{\left(\theta^{\prime} w\right)^{2}}\right]\left(\beta^{\prime} y\right)^{2}+\Lambda z+0.5 \theta\left(z^{\prime} \Gamma z\right)
$$

\footnotetext{
${ }^{11}$ Khumbakar (1994) proposes a different extension of the McFadden to the multiproduct case.
} 


\section{WeLFARE TRADEOFFS IN U.S. RAIL MERgERS}

This defines the second element of our structural model - a set of $I$ input demand equations for factors of production. In our model we identify four such factors - fuel, labor, materials and equipment as described below.

\section{Infrastructure constraint}

Each railroad is active in each of the $G$ markets so that, at the equilibrium, $y_{g h}$ measures the amount of freight managed by railroad $h$ in market $g$. To perform its business the railroad uses rail infrastructure which is another product that the railroad has to produce or to buy from competitors. This is why we consider $G^{\prime}$ products with $G^{\prime}=G+1$. If it is reasonable to assume that deregulated railroads are free to set the levels of such outputs, it is not reasonable to assume that they are unconstrained in their ability to transform operating outputs into infrastructure outputs. Here we assume that the amount of infrastructure $H$, $y_{F h}$, used for operations is approximated by the simple linear relation

$$
y_{F h}=\eta_{0}+\sum_{g=1}^{G} \eta_{g} y_{g h}+\sum_{g>G} \eta_{g} t_{g h}
$$

in which we also account for the effect of technological factors. This equation can be interpreted as an engineering equation to dimension the size of infrastructure. It is the third element in our system of equations.

\section{Pricing}

We incorporate the oligopoly assumption into our theoretical model by adding a set of equilibrium conditions in which each railroad maximizes its profit with respect to prices (or quantities) conditional on the prices (or quantities) set by competitors in the various freight service markets. Letting the subscript $h$ represent firms competing in the markets for rail services $(h=1,2, \ldots, H)$, the objective of each firm is to solve

$$
\operatorname{Max}_{p_{g h} \text { or } y_{g h}} \sum_{g=1}^{G} p_{g h} y_{g h}-C\left(y_{g h}, w_{g h}, t_{g h}\right)
$$

Whether the strategic interaction among firms is in prices or in quantities, on the assumption that the markets for rail services are independent, the first order condition for profit maximization is: 


$$
p_{g h}-c_{g h}=-y_{g h} \frac{\partial p_{g h}}{\partial y_{g h}}
$$

where $c_{g h}$ stands for the marginal cost effect of a change in output level for $y_{g h}$, which accounts for the effect on infrastructure as explained in the preceding section.

Given the specification of the demand function described above, under a multiproduct BertrandNash equilibrium, the first order condition for profit maximization (13) yields the expression of price - cost margins as

$$
p_{g h}-c_{g h}=\frac{1-\sigma_{g}}{\alpha_{g}\left(1-\sigma_{g} s_{g h \mid H}-\left(1-\sigma_{g}\right) s_{g h}\right)} .
$$

If the market corresponds to a Cournot equilibrium, the expression of price - cost margins is now

$$
p_{g h}-c_{g h}=\frac{1}{\alpha_{g}}\left(1+\frac{S_{g h \mid H} S_{g h}}{S_{g h \mid H}-S_{g h}}-\sigma_{g}\left(1-s_{g h \mid H}\right)\right) .
$$

The marginal costs in these expressions is derived by differentiating the cost function with respect to the relevant elements of the output vector $y$ gives the $n$ factor-specific resource requirements for a marginal unit of output. These requirements are monetized using

$$
c=\frac{\partial C}{\partial y}==w^{\prime}\left\{\left[\frac{\Delta w}{\theta^{\prime} w}-0.5 \frac{w^{\prime} \Delta w}{\left(\theta^{\prime} w\right)^{2}}\right]\left(\beta^{\prime} y\right)^{2}+\Lambda^{\prime} z+z^{\prime} \Gamma z\right\} .
$$

where the term in brackets is the projected factor demand vector. Because of the infrastructure constraint, the full marginal cost of an operating output $g(g=1,2, \ldots, G)$ for railroad $h$ is given by

$$
c_{g h}=\frac{\partial C}{\partial y_{g h}}+\eta_{g} \frac{\partial C}{\partial y_{F h}}
$$




\section{WeLFARE TRADEOFFS IN U.S. RAIL MERgERS}

since it must include the direct operating effect of a change in output and an indirect effect though the change in the use of infrastructure.

Equations (15) or (16) constitute the fourth (and final) element of our structural model.

\section{Data}

We focus on a sample of 26 Class I rail companies that operated between 1986 and 2001 as shown in Table 3. The primary sources for the data are Analysis of Class I Railroads published annually by the AAR and the AAR Railroad Cost Indexes. The Analysis is based on regulatory accounting data that railroads submit to the government. The Cost Indexes are synopses of the indices that the AAR is required to file quarterly with the government. Construction of the railroad operating and cost data follows the procedures described in Ivaldi and McCullough (2001).

\section{[INSERT TABLE 3. U.S CLASS I RAILROADS 1986-2001]}

The measure of rail variable costs is based on freight services expenditures. The AAR Analysis (lines 250-259) contains various categories of expenditures for labor, materials and supplies, fuel and power, and others. These are grouped into three categories of expenditures directly interpreted as variable "costs" labor (lines 250, 251), fuel (line 253) and materials and other (lines 252, 254, 257-9). Accounting depreciation is ignored; instead, a fourth component of variable cost defined as the economic cost of equipment use is calculated by the authors and added to the model. The cost of equipment is computed as $\left(\rho_{h t}+\delta\right) X_{E, t}$ where $\rho_{h t}$ is a bond rate that represents the opportunity cost of equipment capital for firm $h$ in year $t, \delta$ is a depreciation rate for equipment, and $X_{E, t}$ is the real value (\$82) of the railroad's equipment capital stock.

For outputs, we use detailed information in the Analysis on loaded car-miles by type and empty carmiles by type for 15 types of equipment: 40 -foot box cars, 50 -foot box cars, plain gondola, etc. The 15 cartype miles are aggregated (by addition) into BULK car-miles $\left(y_{b}\right)$, GENERAL freight car-miles $\left(y_{e}\right)$ and INTERMODAL freight car-miles $\left(y_{v}\right)$. The $y_{b}$ category includes all open hopper (typically coal) and 
closed hopper (typically grain) cars. The $y_{e}$ category includes all other car-types except intermodal. Use of the car-mile rather than the ton-mile as a unit of output allows us to take into account differences in the technological characteristics of rail operations. This aggregation does not force us to ignore the differential cost effects of weight since the cars in the $y_{v}$ and $y_{e}$ category typically range between 20 and 60 tons and those in the $y_{b}$ category range between 80 and 100 tons.

One important way in which our cost model differs from both earlier rail models and structural merger models in other industries is in its explicit treatment of infrastructure activity. We view the infrastructure-related activities of the firm as variable outputs which impose costs directly and which interact with other (operational) outputs. ${ }^{13}$ The output measure for infrastructure is the annual number of TIES-LAID-IN-REPLACEMENT $\left(y_{i}\right)$ by each railroad in our sample. ${ }^{14}$ This allows us to account for the technological aspects of vertical as well as horizontal integration and to take into account the unique cost characteristics of network firms which are required to maintain their own infrastructure.

For input prices, we use annual input price indices for FUEL, LABOR and MATERIALS assembled by the AAR and based on surveys of prices paid by member firms. The EQUIPMENT price is the ex ante yield on bonds in a firm's debt category for a given year and a depreciation component. The depreciation component is calculated by solving for a rate that allows equipment to decay exponentially to a 10 per cent salvage value in 25 years.

The technological variables in our model are TIME, and length of haul (HAUL), miles of road (ROAD), and percent unit-train car-miles (UNIT) from the Analysis. We follow Vellturo (1989) in using a set of exogenous, demand-related variables, that can be constructed on a firm-specific basis. These variables--coal consumption (CCON), coal production (CPRO), new car deliveries (NEWCAR), state population (SPOP), and oil price (OILP)--are measured on a state-by-state basis and then aggregated across states by to be railroad-specific. The aggregations vary from year to year as railroad organizations restructure and add or discontinue route segments. They are based on annual data from the AAR., the U.S. Energy Information Administration, and the Statistical Abstract of the U.S.

Construction of a data series representing railroad pricing decisions in this period is not as straightforward as assembling the production and cost data. Pricing information is available in the Official Waybill Sample which the STB collects for regulatory purposes but the detailed records are confidential at

\footnotetext{
${ }^{13}$ In most rail cost studies such as Berndt et al (1993) infrastructure is treated as a quasi-fixed input and represented by a monetary measure of way and structures capital. Wilson (1997) is an exception.

${ }^{14}$ It is important to note in this respect that about 90 percent of the ties laid each year by Class I railroads are replacement ties. To see this, compare Line 350 of the Analysis (Ties Laid in Replacement) with Line 363 (Ties Laid in Addition).
} 


\section{WeLFARE TRADEOFFS IN U.S. RAIL MERgERS}

the request of both railroads and their customers. Nor does the AAR make pricing information directly available in the Analysis. The Analysis reports revenues by commodity, tons by commodity, and carloads by commodity, but it does not report commodity specific information by ton-miles or car-miles. This means it is not possible to directly estimate proxies for rates (average revenues) which reflect commodity, weight, and distance.

Nevertheless, we feel it is possible to combine the information in the Public Waybill and the Analysis to build such series indirectly. The reason is that the car-mile outputs that we have identified ( $y_{b}$, $y_{e}$, and $y_{v}$ ) can be fairly closely linked to commodity groups. We first use the commodity-specific revenue and carload data in the Analysis to calculate the average revenue-per car-mile associated with certain sets of commodities (grain and coal, for example) and, by implication with certain car-types (closed-hopper and open-hopper). We then use the firm-level revenue data in the Analysis to allocate these average rates to the individual railroads using a Laspeyres index. To check these estimates we use an "official" set of aggregate (industry-wide) price estimates from STB (2000). The estimated average rates are as seen in Table 4.

\section{[INSERT TABLE 4. ESTIMATED REVENUE PER CAR-MILE]}

An adjustment to the rates is necessary. The rates that we calculate are for loaded car-miles. In fact, the railroad must absorb the costs of the loaded and empty portions of each movement. Also, the marginal costs to which these rates are compared are estimated by us on a total car-mile basis. To reflect these facts, we calculate for each car-type an "effective rate", i.e., an estimate of the distributed rate the railroad typically receives for moving a particular car-type one mile. We do this by calculating the ratio of loaded to empty miles by car-type from data in the Analysis. We then use this ratio to form a "payment factor" which converts the loaded car-mile rate into an effective (i.e., distributed) car-mile rate. The payment factor is simply the share of loaded car-miles in the sum of loaded and empty car-miles.

One final clarification is necessary. While, on the commercial side, the distinction between bulk, general and intermodal freight is apparent in the different rates charged for moving these commodities, on the production side general freight and intermodal operations are fairly similar on the production side. We account for this by using two operating output categories $y_{b}$ and $y_{e}+y_{v}$ in the cost-related equations and three outputs $y_{b}, y_{e}$ and $y_{v}$ in the demand and pricing equations. 


\section{Estimation Results}

The model established in Section III requires us to estimate alternative systems of equations, depending on whether we are assuming Bertrand competition in prices or Cournot competition in capacities. Each system is composed of 11 equations - four factor shares for labor, fuel, materials and equipment to establish marginal costs, three demand equations for bulk, general freight and intermodal rail services, behavioral equations (Bertrand or Cournot) for these three markets, and a transformation equation to constrain the technology. In fact, there are multiple systems to estimate since there is no reason to assume that firms will adopt uniform Bertrand or Cournot strategies in all three markets. It is equally likely a priori that they could adopt Bertrand strategies in one or two of the markets and Cournot in the other(s). This gives us the eight alternative strategies represented in Table 5 - Bertrand in bulk, general and intermodal (BBB), Bertrand in bulk and general but Cournot in intermodal (BBC), and so on. We evaluate these alternatives using a likelihood ratio test of Vuong (1989) to identify the best model or models. We then use the selected model or models to draw inferences about the effect of mergers in these markets.

Each equilibrium model is estimated by means of nonlinear three stage least squares (NL3SLS), which requires us to define a set of instruments. The set includes the factor prices for labor, fuel, equipment and materials, the technological variables, the demand-related variables, the variables CARB, CARE, AND CARV which express firm-level railroad capacities in cars, and the variables AGCAPB, AGCAPE, and AGCAPV, which express firm-level capacities in tons.

\section{A. Vuong Test Results}

Let $f_{j}\left(y_{i} \mid x_{i}\right)$ be the predicted probability that a random variable $\mathrm{Y}$ is $y_{i}$ under the assumption that $f_{j}\left(y_{i} \mid x_{i}\right)$ generated the data. The Vuong statistic as described by Greene (2003) for testing the non-nested hypothesis of $f_{1}$ versus $f_{2}$ is

$$
v=\frac{\sqrt{n}\left[\frac{1}{n} \sum m_{i}\right]}{\sqrt{\frac{1}{n} \sum\left(m_{i}-\bar{m}\right)^{2}}},
$$




\section{Welfare TRADEOFFs IN U.S. RaIL MERGERS}

where $m_{i}=\log \left(\frac{f_{1}\left(y_{i} \mid x_{i}\right)}{f_{2}\left(y_{i} \mid x_{i}\right)}\right)$. If $|v|$ is less than 2, the Vuong test does not favor one model or the other. Otherwise, positive values favor $f_{1}$ while negative values favor $f_{2}$. The results in Table 5 are not entirely conclusive since we cannot eliminate either the $\mathrm{BCC}$ alternative or the $\mathrm{CCC}$ alternative. Clearly behavior in the general freight and intermodal markets is Cournot, but the Vuong results suggest that behavior in the bulk market could be either Bertrand or Cournot.

\section{[INSERT TABLE 5. VUONG TEST COMPARISONS]}

This possibility is not surprising. Since passage of the Staggers Act the majority of bulk traffic has been moving under contract agreements between railroads and shippers. These contracts, which were prohibited as discriminatory before Staggers, are relatively short-term agreements negotiated between wellinformed shipping executives for coal, grain and chemical companies (many of whom deal with multiple railroad carriers) and well-informed railroad executives. It is reasonable to expect that the outcome of these negotiations would be a "market price" that reflected both the valuable of the shipments to shippers and the cost to the railroads. ${ }^{15}$ However considerations about available capacities in this market also play a role, which could explain why the market for bulk is not far from the Cournot solution. ${ }^{16}$ It is also reasonable that the general freight and intermodal markets, where there are relatively large numbers of shippers and few railroads, would allow for strategic coordination among railroads a la Cournot. In what follows, we present the results of the BCC scenario but we also indicate where the CCC results are different. In all but a few cases the parameter results are very close.

\section{B. Parameter Estimates}

Estimates of the main parameters of interest are provided in Table 6a below while other parameters of interest are gathered in Table $6 b .{ }^{17}$

[INSERT TABLE 6a. NL3SLS ESTIMATES OF PARAMETERS OF INTEREST]

\section{[INSERT TABLE 6b. PARAMETRIC ESTIMATES]}

\footnotetext{
${ }^{15}$ The Nash equilibrium in the classic Bertrand pricing game is the point where price equals marginal cost. If railroads are natural monopolies (as our cost results suggest) then the Bertrand game with well-informed carriers and shippers will lead to prices above marginal cost which guarantee revenue adequacy. See Laffont and Tirole (1994).

${ }^{16}$ We believe that data on contracts between shippers and railroads are required to investigate the conduct in the bulk market in more detail.

${ }^{17}$ The full list of 137 parameter estimates and standard errors is presented in Table A of the supplemental document to this text.
} 
These key structural parameters in Table 6a reflect shipper sensitivity to prices $\left(\alpha_{b}, \alpha_{e}\right.$, and $\left.\alpha_{v}\right)$ and to differentiation between transport modes $\left(\sigma_{b}, \sigma_{e}\right.$, and $\left.\sigma_{v}\right)$. They all are significant, the former having the proper positive sign and the latter being positive and less than one which guarantees that the model is consistent with utility maximization. They all are well identified by the set of instruments selected for the estimation. The first stage R-square statistics associated with these parameters are not lower than 98 percent. ${ }^{18}$ The $\sigma$ 's values indicate that the preferences of shippers in the bulk and intermodal freight markets are more correlated across railroads than between railroads and other transport modes. Railroads appear to be more differentiated among themselves in the general freight market. As a consequence, bulk and intermodal movements are less sensitive to competition from other modes than general freight movements.

Moving to Table $6 \mathrm{~b}$, we first observe the relatively high values of demand elasticities. This is not surprising in this context since these elasticities do not bear on the market as a whole but apply to each railroad. These elasticities suggest that at the observed equilibrium competition is at work. The results also suggest that the overall demand for railroad freight services in each of the three markets we identify is primarily dependent on the size of the network on which the railroad operates and on the level of economic activity along that network. For the bulk and intermodal freight markets our model identifies new car deliveries as the most important variable and in the general freight market the relevant variable is state population. These results are consistent with earlier and more specialized studies that establish the derived nature of freight demand.

The parametric estimates of railroad costs and technology are extrapolated from the results of the McFadden Cost function. Use of this flexible functional form in a structural merger analysis is a key element of this paper. Earlier studies have used simpler functional forms such as constant marginal costs and thus have omitted the possibility of non-homothetic relationships across inputs or outputs. This is a serious limitation in econometric merger studies since economies of scope and/or scale are often an important component of the efficiency claims made by merger proponents. ${ }^{19}$

The most important results on the cost side are the marginal cost estimates which play a key role in the pricing equations and in the analysis of consumer surplus. Marginal cost estimates for $y_{b}, y_{e}$ and $y_{v}$ and $y_{i}$ are estimated by as the weighted sum of partial derivative of factor demands by input prices. The effects of technology and second-order output related effects are estimated using similar extrapolations.

The first point to notice is that the marginal costs of bulk services vary considerably from those of general freight and intermodal services. The average value for the marginal cost of bulk services is $\$ 0.45$

\footnotetext{
${ }^{18}$ These first-stage R-square are also provided in Table A of the supplemental document.

${ }^{19}$ It is also interesting to note in this regard that a flexible functional form like the McFadden imposes more structure on the overall model. The lack of structure in earlier merger model may explain why many of these studies have had to utilize larger number of instrumental variables to get their models to converge.
} 


\section{Welfare TRADEOFFs IN U.S. RaIL MERGERS}

while the value for general freight and intermodal services is $\$ 0.82$. These estimates, which are independent of infrastructure costs, are consistent with expectations since general freight and intermodal services involve a higher degree of operational complexity - marshaling at yards, blocking strategies for cars, complex scheduling and repositioning of crews and locomotives. Unit train operations, on the other hand, involve regular, trolley-like movements between origins and destinations. ${ }^{20}$ For all of these movements the estimated marginal costs are below ray average variable costs in this data which are \$1.26 per car-mile.

A second point to notice is the marginal effect of the use of infrastructure in the course of operations. Our results imply that the cost basis for the fee which a railroad should charge another railroad to use its network for bulk carriage is $\$ 0.07$ per car-mile, while the cost basis for a general freight access fees should be $\$ 0.017 .^{21}$ These fees are close to the fees actually charged by railroads that are filed with the STB.

A third point to notice about this technology is that there is evidence of efficiency gains from increases in length of haul. Railroads have argued that these are facilitated by end-to-end mergers and our calculations suggest that a ten percent increase in length of haul will lead to 0.9 percent reduction in variable costs. These gains are comparable to the 5.5 percent annual cost reduction attributable to technological change.

Finally, we note that estimated returns to density for operations are 1.94. From a regulatory and welfare perspective this means that in order to be revenue adequate railroads must charge prices that are above marginal costs, and [following Baumol (1982)] that the markups should be differentiated to reflect differences in marginal costs and elasticities of demand. The actual differences are seen below in our estimates of railroad Lerner indices and in the welfare effects which would be more crudely estimated had we used a simpler functional form for costs. ${ }^{23}$

\section{Monopoly Effects}

The primary aim of this research is to evaluate the welfare effects of the structural changes that have taken place in the U.S. railroad industry since the Staggers Act in 1980. Since that time, a handful of U.S. railroads have increased their market shares dramatically, but they have also reduced their labor forces and

\footnotetext{
${ }^{20}$ The higher infrastructure costs that these operations impose are identified in our model in the estimated marginal cost of infrastructure activities which we put at $\$ 285.90$ per replacement tie.

${ }^{21}$ We use the term "cost basis" to reflect the fact that in order to guarantee revenue adequacy access fees should also reflect demand based markups over marginal cost.

${ }^{23}$ We also find evidence of cost complementarities between bulk and general freight operations. These are indicated by a negative second-order coefficient for $y_{b}$ and $y_{e}$ in the McFadden cost equation. Ivaldi and McCullough (2004) provide a detailed analysis of railroad economies of scope using the McFadden cost function.
} 
their physical plants and there is evidence is that they have shared these efficiency gains to their customers in the form of lower real rates. The question then is what are the overall effects of these structural changes?

The measure we use is the change in overall consumer surplus in the markets for bulk, general freight and intermodal rail services, where net consumer surplus is given by the expected value of the maximum of utilities. Using the assumptions of the nested logit model developed in Section III this net consumer surplus measure is:

$$
C S_{g}=\frac{1}{\alpha_{g}} \ln \left(1+D_{g}^{1-\sigma_{g}}\right)
$$

This formula is derived in Anderson, de Palma and Thisse (1993). ${ }^{24}$

\section{[INSERT TABLE 7. CONSUMER SURPLUS TRENDS ]}

The results of these calculations are presented in Table 7. (See also Figures 1 and 2.) They show that during the period from 1986 to 2001 consumer surplus grew by 25 percent from $\$ 1.3$ billion to $\$ 1.7$ billion, and this despite a significant drop in welfare after 1999. There was steady, dramatic growth from 1986 to 1993 but the growth of consumer surplus became somewhat erratic after that. The BNSF and UPSP mega-mergers were accompanied by a drop in consumer surplus in 1996 but there was a recovery the following year. There was another drop in consumer surplus in 2000 following the division of Conrail between NSC and CSX and this downward trend continued in 2001. It is unclear whether these results are a temporary setback in consumer surplus or signal a downward trend that can be attributed to the megamergers. Nevertheless it does appear that the benefits in surplus from the large mergers of the late 1980s and early 1990s had a more positive effect on surplus than the controversial mega-mergers.

If we look at the results market-by-market we see that all three markets exhibit the same pattern of uneven growth. The most dramatic growth in surplus is in intermodal (32 percent), followed by general freight (29 percent) and bulk (19 percent). ${ }^{25}$ One caveat about these results is that our data does not identify the relative size of the shippers. There is anecdotal evidence from regulatory and legislative proceedings that smaller shippers in all three categories do not benefit as much as large shippers (if at all).

\footnotetext{
${ }^{24}$ Since the markets served by freight railroad firms are factor markets, it is not necessarily the case that the surplus generated in these markets is completely passed on to consumers. This will depend on market structure and behavior in downstream markets. To fully model these effects would require a general equilibrium model that is beyond the scope of this paper and beyond the requirements of current merger practice.

${ }^{25}$ Note that bulk shippers are the ones who most strongly opposed the Staggers Act while a coalition of general freight shippers in the chemical and auto industry most effectively supported it.
} 


\section{Welfare TRADEOFFs IN U.S. RaIL MERGERS}

Surplus trends exhibit the same basic growth pattern if we maintain the CCC hypothesis of Cournot behavior in the bulk market as well as in general freight and intermodal but (as expected) the magnitude of surplus is much lower in the bulk market. The initial level of surplus in bulk in 1986 under Cournot behavior is only $\$ 82.5$ million (versus $\$ 625$ million under Bertrand pricing). This reduces the overall level of surplus in 1986 to $\$ 818$ million (versus $\$ 1.4$ billion under Bertrand pricing). The 2001 level for bulk under Cournot behavior is $\$ 91.7$ million and the overall level of surplus is $\$ 1.04$ billion.

\section{Lerner Indices}

The focus of this paper is on the effects of structural changes in the market for rail freight services in the U.S. We have focused in Section $5 c$ on temporal movements in consumer surplus. Nevertheless, as we have noted above, the evidence from the cost function presented above as well as from many earlier studies of railroad technology suggests that if railroads were to charge rates equal to marginal cost they would fail to be revenue adequate. In multiproduct firms these markups should reflect differences in the marginal costs of services and well as in their elasticity of demand. Rail regulatory policy in the U.S. explicitly mandates that railroads should charge differentiated markups above marginal cost in order to remain viable.

The structural model that we present here allows us to provide proper estimates of these markups in the form of estimated Lerner indices which reflect the influences of both supply and demand. The estimates of these indices for the four largest railroad firms are presented in Table 8 To eliminate temporal bias they are averaged over the period 1992-2002 .

\section{[INSERT TABLE 8. LERNER INDICES BY SEGMENT]}

The relative magnitudes and distributions of these indices across firms and across service offerings are consistent with out expectations based on know market characteristics.

The smallest markups are in the intermodal markets for the two eastern carriers CSX ( 25 percent) and NSC (22 percent). These railroads are competing with truckers and with each other for the relatively short-hauls on higher value commodities in the populous eastern portion of the U.S. Intermodal markups are higher for ATSF (ATSF, 46 percent) and SP (39 percent) in the western U.S. where longer distances give rail intermodal movements a potential advantage over long distance truck movements.

Markups for eastern railroads also are lower in the market for general freight services but overall markups in this category are higher than those in intermodal. CSX margins are 69 percent and NSC margins are 67 percent. ATSF and SP have margins of 67 percent and 68 percent respectively. The major commodity groups represented here - primarily those that move in boxcars - are paper, food, lumber, automotive parts, and finished chemicals. There is significant competition from trucks in these markets, but 
railroads have a significant technological advantage in cases where the usage rates are high enough to justify boxcar quantity shipments (and where the shipper has a readily available railroad siding). ${ }^{26}$ Markups in the west and in the east are close, showing that the length of haul does not play much role in the competition with trucks and that Cournot competition among railroads is fierce.

It is of course no surprise that the margins on bulk movements are significantly higher than those for intermodal and general freight. Though there are barge (and even truck) alternatives for shippers of bulk commodities many bulk shippers must rely on one or two railroads to move their commodities to market. Our estimates show CSX enjoying the highest markups ( 85 percent), followed by NSC (77 percent), SP (72 percent), and ATSF (77 percent).

A caveat here is that differences in markups across railroads and across commodities might also reflect technological aspects which are not in our model such as quality of rail service and (in the case of coal or grain especially) the quality of the commodity.

\section{Conclusion}

The importance of mergers in defining the structure of the U.S. railroad industry can be illustrated by briefly recounting the history of the first U.S. railroad, the Baltimore and Ohio (B\&O). During the first wave of rail mergers in the 19th century the $\mathrm{B} \& \mathrm{O}$ expanded west from Baltimore by merger and consolidation until it reached Chicago in 1874. It then operated as a separate entity until the post-World War II second wave, when it was acquired by the Chesapeake and Ohio in 1962. It was merged into the Chessie System in 1973 and in 1980, at the beginning of the third wave, the Chessie System was integrated into CSX. In 1998 CSX acquired half of Conrail and emerged as one of two dominant systems operating in the eastern half of the U.S.. The outstanding question now is whether CSX will merge with a rail system in the western U.S. to extend beyond Chicago to the Pacific Ocean.

The primary focus in this paper has been on the development and application of a structural econometric model for evaluating such rail mergers. We have presented a system of equations which express 1) the demand conditions prevailing in the bulk, general freight and intermodal markets, 2) cost conditions in these markets, and 3) hypotheses regarding the strategic behavior of railroad firms participating in the markets. We build on the work of Anderson, de Palma and Thisse (1992), Berry (1994), Shapiro (1996), Hausman and Leonard (1997), Nevo (2000), Ivaldi and Verboven (2000), and others who

\footnotetext{
${ }^{26}$ In rough terms, our results show that the average cost of a car-mile is $\$ 1.07$ which is slightly more than the estimated cost of a truck-mile. A located box car hauls two to three times as much freight as a truckload.
} 


\section{Welfare TRADEOFFs IN U.S. RaIL MERGERS}

have developed the theory of differentiated product markets into a tool for merger analysis and attempt to extend the work by using a flexible cost function to incorporate parametric estimates of merger efficiencies into the model. We also evaluate actual (as opposed to simulated) merger effects.

The empirical finding of the paper is that consumer surplus in rail freight markets has increased by about 25 per cent despite the consolidation of 36 Class I railroad firms into nine. This finding is not inconsistent with results from other researchers who have studied the transformation of the U.S. railroad industry in the last quarter of the $20^{\text {th }}$ Century.

\section{References}

Anderson, S., de Palma, A. and Thisse, J.F. (1992), "Discrete Choice Theory of Product Differentiation," Cambridge: MIT Press.

Burton, M. L. (1993), "'Railroad Deregulation, Carrier Behavior, and Shipper Response: A Disaggregated Analysis," Journal of Regulatory Economics, 23(3), 309-333.

Berndt, E, Friedlaender, A., Wang Chiang, J., and Vellturo, C. (1993) "Cost Effects of Mergers and Deregulation in the U.S. Rail Industry," The Journal of Productivity Analysis, 4, 127-144.

Berry, S.T. (1994), "Estimating Discrete-Choice Models of Oligopoly Product Differentiation," The Rand Journal of Economics, 25 (2), 242-262.

Breen, Dennis A. (2004), The Union Pacific/Southern Pacific Rail Merger: A Retrospective on Merger Benefits." FTC Working Paper.

European Commission (2004, "Guidelines on the Assessment of Horizontal Mergers under the Council Regulation on the Control of Concentrations between Undertakings, Official Journal, C 31, 05.02.2004, 5-18.

Gasmi, F. and Vuong, Q. H. (1991), "An Econometric Analysis of some Duopolistic Games in Prices and Advertising," Advanced in Econometrics, 9, 225-254.

Grimm, C. and Winston, C. (2000), "Competition in the Dergulated Railroad Industry: Sources, Effects, and Policy Issues," in Peltzman S. and Winston, C. Deregulation of Network Industries Brookings, 2000

Hausman, J. and Leonard, G. (1997), "Economic Analysis of Differentiated Product Mergers Using Real World Data," George Mason Law Review, 5(3), 312-346.

Ivaldi, M. and McCullough, G. (2001), "Density and Integration Effects on Class I U.S. Freight Railroads," Journal of Regulatory Economics, 19 (2), 161-182.

Ivaldi, M. and Verboven, F. (2000), "The European Heavy Trucks Market: An Econometric Analysis.", Working Paper, IDEI.

McFadden, D. (1981), "Econometric Models of Probabilistic Choice," in C.F. Manski and McFadden (eds.), Structural Analysis of Discrete Data with Econometric Applications, Cambridge: MIT Press, 198-272.

Nevo, A. (2000), "Mergers with Differentiated Products: The Case of Ready-to-Eat Cereal Industry," The Rand Journal of Economics, 31(3), 395-421.

Röller, L-H. and Sickles R.C. (2000), "Capacity and Product Market Competition: Measuring Market Power in a 'Puppy-dog" Industry," International Journal of Industrial Organization, 18, 845-865.

Shapiro, C. (1996), "Mergers with Differentiated Products," Antitrust, 23-30.

Surface Transportation Board (2003) Rules Governing Major Railroad Mergers and Consolidations. Washington, D.C.

Vellturo, C. A. (1989), "Achieving Cost Efficiencies Through Merger: Evidence from the U.S. Rail Industry," Cambridge, Mass.: MIT, Department of Economics, Unpublished Ph.D. dissertation. 
Verboven, F. (1996), "International Price Discrimination in the European Car Market," Rand Journal of Economics, 27 (2), 240-268.

Vuong, Q. H. (1989), "Likelihood Ratio Tests for Model Selection and Non-nested Hypotheses," Econometrica, 57, 307-333.

Williamson, O. E. (1968), "Economies as an Antitrust Defense: Welfare Tradeoffs," The American Economic Review, 58(1), 18-36.

Wilson, W; W. (1997), "Cost Savings and Productivity in the Railroad Industry," Journal of Regulatory Economics, 11, 21-40.

Wilner, F. H. (1997). Railroad Mergers. Simmons-Boardman. Omaha, Nebraska

Winston, C. (1985), "Conceptual Developments in the Economics of Transportation: An Interpretative Survey," Journal of Economic Literature, 23, 57-94. 


\section{Welfare TradeOFFs in U.S. RaIL MERgers}

Table 1. Significant Railroad Unifications - 1986-2001

\begin{tabular}{lllccc}
\hline Year & Merging Firms & $\begin{array}{c}\text { Merged } \\
\text { Firm }\end{array}$ & $\begin{array}{c}\text { Combined } \\
\text { Employees }\end{array}$ & $\begin{array}{c}\text { Combined } \\
\text { Route Miles }\end{array}$ & $\begin{array}{c}\text { Combined } \\
\text { Revenue } \$ 82\end{array}$ \\
\hline 1986 & Chessie/Seaboard & CSX & 47,803 & 22,887 & 4.56 \\
1986 & N\&W/Southern & NSC & 34,857 & 17,520 & 3.36 \\
1994 & UP/CNW & UP & 35,001 & 22,785 & 5.57 \\
1995 & BN/Santa Fe & BNSF & 43,731 & 35,208 & 6.55 \\
1996 & UP/SoPac & UPSP & 52,533 & 34,946 & 7.80 \\
1999 & CSX/ConRail & CSX & 34,283 & 23,320 & 4.80 \\
1999 & NSC/ConRail & CSX & 33,344 & 21,759 & 4.87 \\
\hline
\end{tabular}

Table 2. Herfindahl Indices - 1985-2000

\begin{tabular}{ccc}
\hline Year & Number of Class I Railroads & Herfindahl Index \\
\hline 1985 & 23 & 837.12 \\
1986 & 18 & 1285.45 \\
1990 & 14 & 1290.56 \\
1995 & 11 & 1363.39 \\
1996 & 10 & 1641.07 \\
1997 & 9 & 1946.00 \\
2000 & 8 & 2246.02 \\
\hline
\end{tabular}

Table 3: U.S Class I Railroads 1985-2000

\begin{tabular}{lc}
\hline \multicolumn{1}{c}{ Railroad (Abbreviation) } & Years \\
\hline Atchison, Topeka \& Santa Fe (ATSF) & $1986-1995$ \\
Burlington Northern (BN) & $1986-1995$ \\
Burlington Northern \& Santa Fe (BNSF) & $1996-2001$ \\
Chicago Northwestern (CNW) & $1986-1994$ \\
Consolidated Rail Corporation (CRC) & $1986-1999$ \\
CSX Corporation (CSX) & $1986-1997$ \\
Delaware \& Hudson (D\&H) & $1986-1987$ \\
Denver, Rio Grande Western DRGW) & $1986-1993$ \\
Florida East Coast (FEC) & $1986-1991$ \\
Illinois Central Gulf (ICG) & $1986-2001$ \\
Kansas City Southern (KCS) & $1986-2001$ \\
Missouri-Kansas-Texas (MKT) & $1986-1987$ \\
Norfolk Southern Corporation (NSC) & $1986-1997$ \\
SOO Line (SOO) & $1986-1995$ \\
Southern Pacific (SP) & $1986-1996$ \\
Union Pacific (UP) & $1986-1996$ \\
Union Pacific Southern Pacific (UPSP) & $1997-2001$ \\
\hline
\end{tabular}


Table 4. Estimated Average Rail Rates Car-type /Car-mile

\begin{tabular}{llrrc}
\hline Commodity & \multicolumn{1}{c}{ Car-Type } & Revenue & \multicolumn{1}{c}{ Car-miles } & Waybill Rates \\
\hline Grain & Closed Hopper & $3,172,004,665$ & $1,524,484,527$ & 2.08 \\
Coal & Open Hopper & $9,488,758,723$ & $5,523,055,208$ & 1.72 \\
Lumber & Box Car & $2,242,360,766$ & $930,938,180$ & 2.41 \\
Food & Box Car & $3,182,308,909$ & $1,530,824,235$ & 2.08 \\
Paper & Box Car & $2,207,102,824$ & $927,651,262$ & 2.38 \\
Chemicals & Tank & $5,618,582,468$ & $1,797,887,468$ & 3.13 \\
Automotive & Boxcar/Multilevel & $5,021,832,896$ & $2,051,719,778$ & 2.45 \\
Intermodal & Intermodal Flat & $5,012,749,322$ & $10,173,825,469$ & 0.49 \\
\hline
\end{tabular}

Table 5. Vuong Test Comparisons for Alternative Strategic Behaviors

\begin{tabular}{lrrrrrrr}
\hline & BBB & BBC & BCB & BCC & CBB & CBC & CCB \\
\hline BBC & -2.07 & & & & & & \\
BCB & 1.64 & 2.48 & & & & & \\
BCC & $\mathbf{- 2 . 8 3}$ & $\mathbf{- 1 . 2 7}$ & $\mathbf{- 3 . 6 1}$ & & & & \\
CBB & 0.35 & 2.10 & -0.76 & $\mathbf{2 . 7 3}$ & & & \\
CBC & -1.48 & 0.86 & -1.89 & $\mathbf{1 . 5 1}$ & -1.84 & & \\
CCB & 1.42 & 2.50 & 0.33 & $\mathbf{3 . 5 1}$ & 1.47 & 2.19 & \\
CCC & $\mathbf{- 2 . 6 6}$ & $\mathbf{- 1 . 1 8}$ & $\mathbf{- 3 . 3 3}$ & $\mathbf{- 0 . 0 3}$ & $\mathbf{- 3 . 0 0}$ & $\mathbf{- 1 . 9 9}$ & $\mathbf{- 3 . 7 8}$ \\
\hline
\end{tabular}


Table 6a. NL3SLS Estimates of Parameters of Interest

\begin{tabular}{lcccccc}
\hline Market & \multicolumn{2}{c}{ Bulk } & \multicolumn{2}{c}{ General freight } & \multicolumn{2}{c}{ Intermodal freight } \\
\hline Parameter & $\alpha_{b}$ & $\sigma_{b}$ & $\alpha_{e}$ & $\sigma_{e}$ & $\alpha_{v}$ & $\sigma_{v}$ \\
Estimate & 0.0924 & 0.8805 & 0.2301 & 0.6647 & 0.4304 & 0.9101 \\
$t$-value & 2.1 & 16.0 & 10.67 & 15.75 & 8.62 & 24.84 \\
\hline
\end{tabular}

Table 6b. Parametric Estimates

\begin{tabular}{|c|c|c|c|c|}
\hline Equation & Product & Variable & Mean value $^{1}$ & St. Deviation $^{2}$ \\
\hline \multirow{12}{*}{ Demand } & \multirow{4}{*}{ Bulk } & Marginal effect - system size & $7.06 \times 10^{-6}$ & $8.99 \times 10^{-6}$ \\
\hline & & Marginal effect - Car deliveries & $1.13 \times 10^{-7}$ & $7.22 \times 10^{-8}$ \\
\hline & & Own price elasticity & -1.3879 & 0.14 \\
\hline & & Cross price elasticity & 0.0074 & 0.01 \\
\hline & \multirow{4}{*}{ General freight } & Marginal effect - System size & $1.70 \times 10^{-5}$ & $7.01 \times 10^{-6}$ \\
\hline & & Marginal effect - Population & $6.74 \times 10^{-6}$ & $2.50 \times 10^{-6}$ \\
\hline & & Own price elasticity & -1.6325 & 0.16 \\
\hline & & Cross price elasticity & 0.0064 & 0.01 \\
\hline & \multirow{4}{*}{ Intermodal freight } & Marginal effect - System size & $1.20 \times 10^{-5}$ & $8.11 \times 10^{-6}$ \\
\hline & & Marginal effect - Car deliveries & $8.87 \times 10^{-8}$ & $6.91 \times 10^{-8}$ \\
\hline & & Own price elasticity & -5.6838 & 2.10 \\
\hline & & Cross price elasticity & 0.0091 & 0.01 \\
\hline \multirow{9}{*}{ Cost } & Bulk & \multirow[t]{4}{*}{ Marginal cost } & 0.4486 & 0.45 \\
\hline & General freight & & 0.8193 & 0.38 \\
\hline & Intermodal freight & & 0.8193 & 0.38 \\
\hline & Infrastructure & & 173.3974 & 482.57 \\
\hline & Bulk & \multirow[t]{2}{*}{ Access fee to infrastructure } & 0.0722 & 0.20 \\
\hline & General/Intermodal & & 0.0175 & 0.05 \\
\hline & & Returns to length of haul & -0.0500 & 0.08 \\
\hline & & Returns to technical progress & -0.0571 & 0.03 \\
\hline & & Returns to scale & 1.9452 & 2.93 \\
\hline
\end{tabular}

Note: We report the mean (1) and the standard deviations (2) of the empirical distributions of variables except when the parameters (in general the marginal effects) are directly estimated in which case we report the standard errors. 
Table 7. Consumer Surplus Trends (Current Dollars )

\begin{tabular}{ccccc}
\hline Year & Bulk & General freight & Intermodal freight & Total \\
\hline 1986 & $625,843,921$ & $595,537,201$ & $150,970,245$ & $1,372,351,369$ \\
1987 & $695,275,640$ & $650,533,482$ & $159,556,791$ & $1,505,365,915$ \\
1988 & $706,084,459$ & $682,498,413$ & $161,092,684$ & $1,549,675,558$ \\
1989 & $693,411,728$ & $705,004,494$ & $180,744,305$ & $1,579,160,529$ \\
1990 & $731,683,472$ & $719,346,860$ & $178,244,316$ & $1,629,274,649$ \\
1991 & $707,651,220$ & $740,038,738$ & $193,425,161$ & $1,641,115,120$ \\
1992 & $780,032,187$ & $771,371,801$ & $198,509,335$ & $1,749,913,324$ \\
1993 & $762,834,413$ & $800,766,675$ & $194,448,785$ & $1,758,049,875$ \\
1994 & $697,726,737$ & $811,321,905$ & $214,225,352$ & $1,723,273,994$ \\
1995 & $718,406,001$ & $835,633,727$ & $241,442,223$ & $1,795,481,952$ \\
1996 & $724,342,827$ & $862,799,011$ & $191,261,897$ & $1,778,403,736$ \\
1997 & $748,968,605$ & $892,761,731$ & $202,355,737$ & $1,844,086,075$ \\
1998 & $846,856,565$ & $737,760,182$ & $201,584,603$ & $1,786,201,352$ \\
1999 & $899,997,860$ & $751,619,928$ & $198,498,102$ & $1,850,115,891$ \\
2000 & $855,986,396$ & $781,935,928$ & $185,278,585$ & $1,823,200,910$ \\
2001 & $748,815,731$ & $769,056,297$ & $199,295,182$ & $1,717,167,211$ \\
\hline
\end{tabular}

Table 8. Lerner indices by Market Segment for Major Firms (in \%)

\begin{tabular}{lcccc}
\hline \multicolumn{1}{c}{ Railroad } & ATSF & SP & CSX & NSC \\
Market & & & & 77 \\
\hline Bulk & 70 & 72 & 85 & 67 \\
General freight & 67 & 68 & 69 & 22 \\
Intermodal freight & 46 & 39 & 25 & \\
\hline
\end{tabular}




\section{Welfare TradeOFFs IN U.S. RaIL MERGers}

Figure 1. Consumer Surplus on all Market Segments

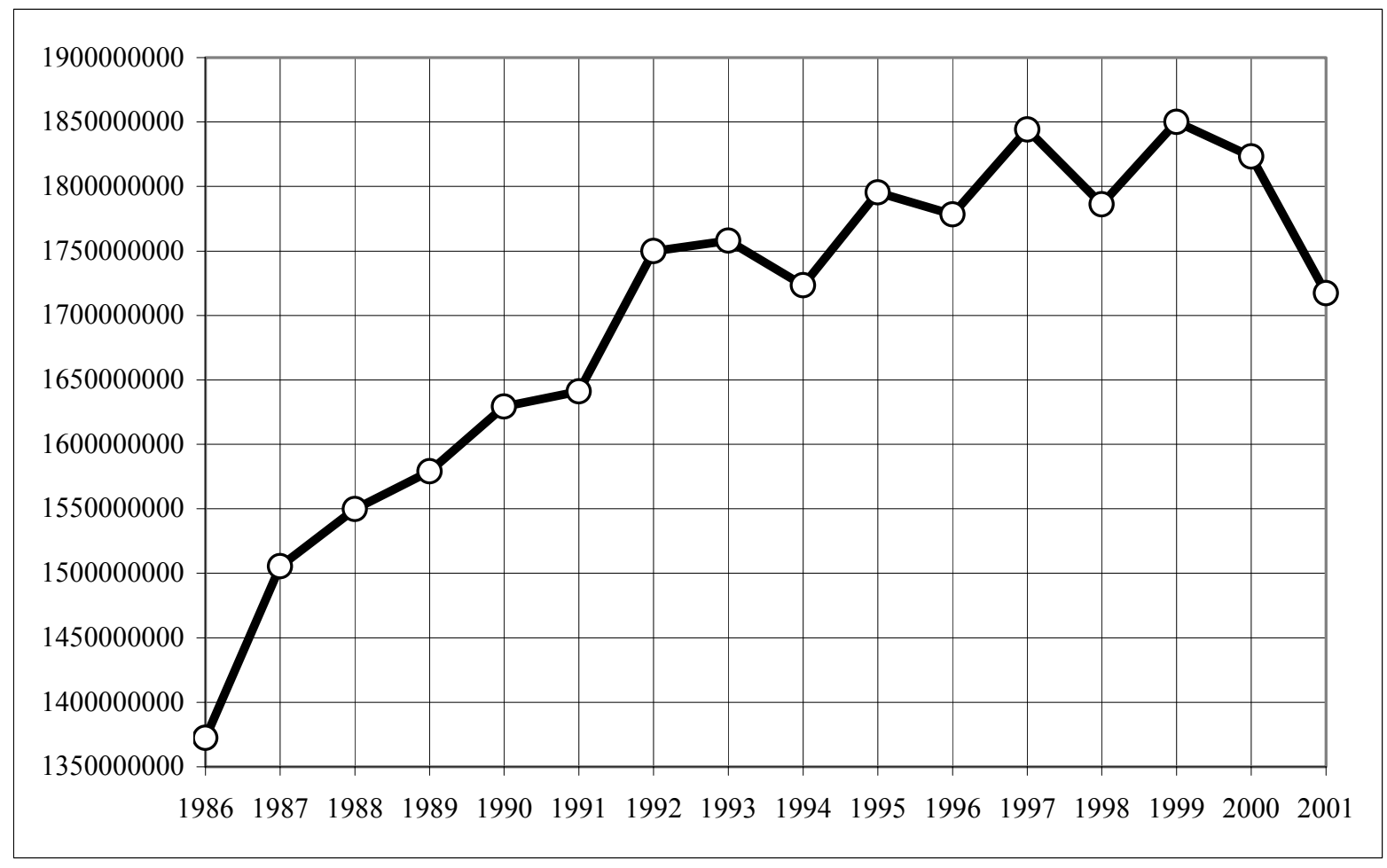

Figure 2. Consumer Surplus by Market Segments

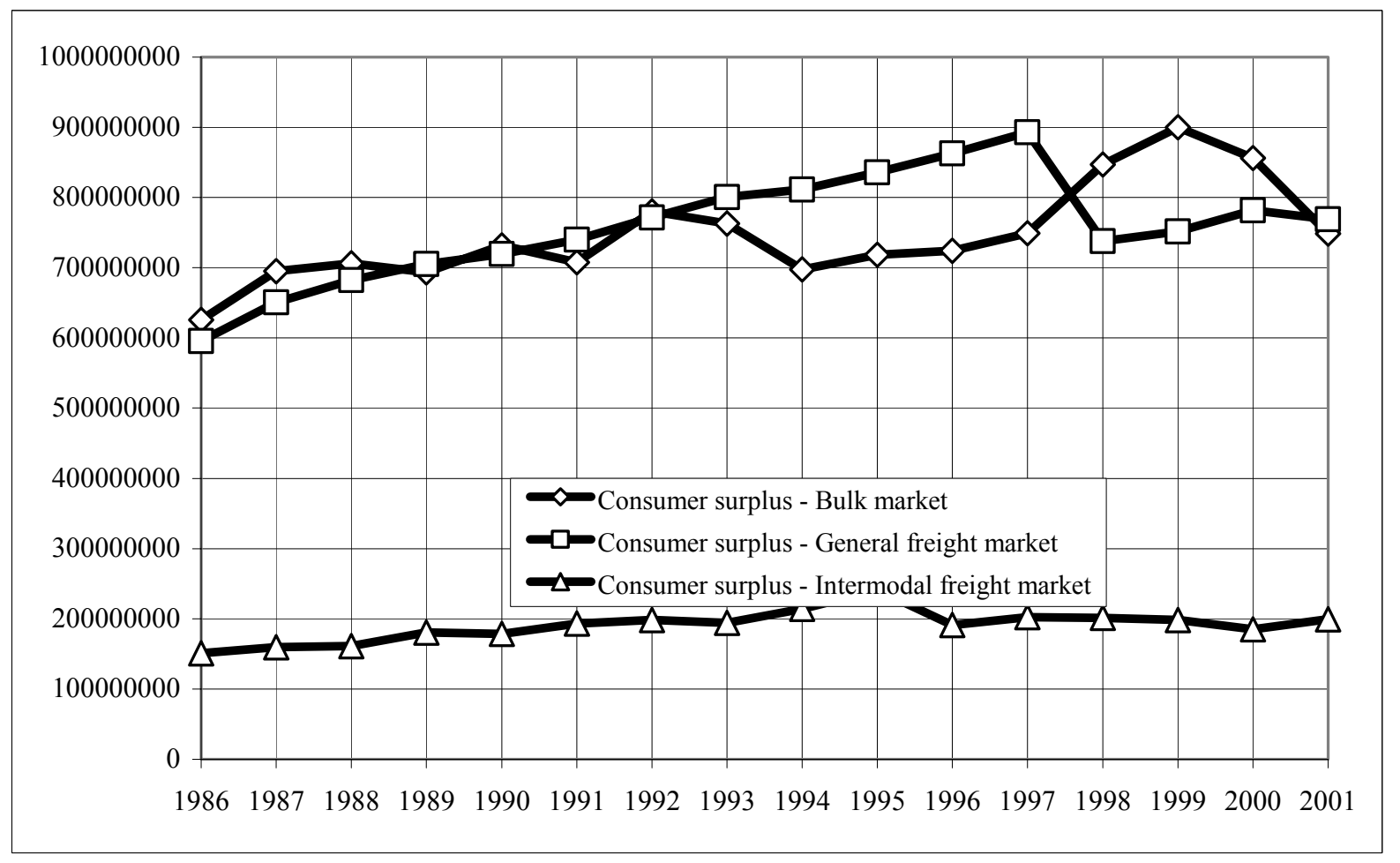

